\title{
Leitura e literatura nas redes: seis casos sobre criar, existir e resistir ${ }^{*}$
}

\author{
Ana Elisa Ribeiro ${ }^{* *}$
}

\section{Considerações iniciais: que redes?}

Nos anos 1990, considerados a década da expansão e mesmo da popularização da internet no Brasil, o sociólogo espanhol Manuel Castells lançou um livro intitulado A era da informação: economia, sociedade e cultura, sendo seu volume $1 \mathrm{o}$ mais conhecido no país, $A$ sociedade em rede. A obra chegou traduzida em português em 1999, pela editora Paz e Terra, com prefácio do sociólogo e ex-presidente Fernando Henrique Cardoso. Foi logo muito lida e citada, tornando Castells uma grande referência no tema das "redes". Àquela altura, a obra tratava das conexões telemáticas que se estruturavam e consolidavam, tecnologicamente, possibilitando uma interconexão global (tanto quanto possível) que envolvia a economia (dinheiro, trabalho, mercado) e a sociedade (redes interativas, informação de massa, interinfluências, fluxos de espaço e tempo, etc.). Segundo conta, Castells investiu doze anos na escrita de $A$ sociedade em rede, título que continua em catálogo no Brasil, com bem mais de uma dezena de edições atualizadas.

A ideia de "rede" transformou-se em uma metáfora produtiva, aplicando-se não apenas às condições infraestruturais sobre as quais funciona a economia ou a mídia no mundo (ou em certa parte hegemônica dele), mas também às relações sociais, em uma mescla inescapável adjetivada de "sociotécnica". Ampliando a ideia de "redes sociais", desde sempre existentes, para uma noção que levava e leva em conta as tecnologias digitais, passou-se a falar em "redes sociais na internet", como propôs Raquel Recuero (2009), considerando que, se as redes tecnológicas conectam também as pessoas, elas são então o que podemos chamar de "redes sociais", sendo um elemento central e importante nas redes sociais as conversações (RECUERO, 2009; 2012).

\footnotetext{
Este texto é uma versão ampliada da comunicação apresentada no VI Encontro de Leitura e Literatura na Universidade do Estado da Bahia (ELLUNEB), realizado em outubro de 2019, em Salvador (BA).

** Doutora em Linguística Aplicada pela UFMG. Docente do Programa de Pós-Graduação em Estudos de Linguagens do Centro Federal de Educação Tecnológica de Minas Gerais (CEFET-MG), Belo Horizonte, MG, Brasil. E-mail: anadigital@gmail.com.
} 
Pierre Musso (2010) chama a atenção para a onipresença, a onipotência e a polissemia da noção de "rede", tomando as "redes" como espaço evidente da leitura e da literatura na contemporaneidade (ou do que há de contemporâneo, mas não apenas). Pode ser interessante lembrar que as redes, nos anos 1990, em especial as conversações, davam-se por meio de e-mails, sites e chats, de forma diferente do que ocorre hoje, quando temos outros tantos recursos, e mais sincrônicos e interativos, como blogs com comentários, "redes sociais" (do extinto Orkut às mais atuais, como Instagram, incluindo ambientes acadêmicos ou profissionais) e aplicativos de todo tipo (para debater todos os assuntos, namorar, etc.), que transferem as redes dos computadores aos dispositivos móveis, tornando-as ubíquas e pervasivas. Já no fim da segunda década do século XXI, essas possibilidades convivem, numa espécie de ecossistema cada vez mais complexo, habitado por milhares de pessoas que se comunicam.

Neste trabalho, a noção de "rede" estará ligada à ideia de conexão entre livros e pessoas, pessoas entre si, em relações menos e mais simétricas, atuando como leitoras, mas também, e principalmente, como produtoras de textos e obras (não necessariamente livros, tal como os conhecemos), criadoras que se preocupam em existir e resistir, inclusive pessoas vivas ou não, autoras de obras que as ultrapassam, considerando contemporâneos os modos de produção, de circulação e de leitura dos textos, embora as conversações e as leituras possam se dar disparadas por obras e autores de outros tempos e espaços.

Interessa-nos a fluência disso, entre o imediato e a memória ou o arquivado, entre autores e autoras vivos/as, leitores e leitoras que reagem (às vezes imediatissimamente) a autores que circulam como espectros ou a discursos que podem ser vistos, debatidos e combatidos via redes sociais digitais. Tais redes são tão vivas quanto aqueles que delas participam, preenchendo seus templates e fazendo o mecanismo girar. E o que podemos dizer de certas experiências de leitura e literatura nas redes?

\section{Leitura e literatura}

Leitura e literatura não existem indistintamente, como sabemos. Ler é o gesto mais amplo de lidar com textos (estes também entendidos em sentido lato), decodificando-os e compreendendo-os, sejam eles anúncios, bilhetes, e-mails, cartazes, poemas ou romances. A leitura literária é uma dentre tantas outras que alguém pode empreender, tomando contato com textos e livros de determinados gêneros, dentre os quais podem estar os considerados então literários. No entanto, a atribuição de valor e prestígio às leituras se dá socialmente, e a leitura literária parece ocupar um lugar distinto em relação a outras, dentre as possibilidades que temos.

Tanto as concepções de leitura quanto às de literatura são diversas, trazendo implicações também variadas. Literatura pode ser só letra, mas pode também ser 
uma arte da oralidade e/ou da vocalidade. Leitura pode dizer respeito ao ato de ler palavras, mas também imagens e muito mais, como muitos pesquisadores brasileiros já alertavam (ver, por exemplo, Lajolo, 1993; Freire, 1982; Freire e Macedo, 1994). Assim também com os letramentos, que vão decorrer dos aprendizados sobre como se lê algo, incluindo conhecimentos mobilizados, rituais, práticas.

A leitura literária tem sido considerada uma competência específica no espectro das leituras possíveis. Para dar conta dela, o letramento literário (Cosson, 2009) tem sido discutido, assim como as questões do livro literário, sem deixar de lado seus endereçamentos, sua produção, sua circulação e o alcance que ele tem em nossa sociedade.

A importância de delinear bem as concepções com as quais trabalhamos ou operamos em nossos estudos, mas também em nossas práticas no mundo, em sociedade, é que, conforme for o "molde" com que atuamos, certos objetos cabem ou não cabem sob nosso olhar. Melhor dizendo: conforme a rede, pegamos este ou aquele tipo/tamanho de peixe. $\mathrm{E}$ com isso nos instrumentalizamos para investigar, por exemplo, a leitura e o/a leitor/a, conforme o que eles fazem, como lidam com textos e obras. A depender do que chamamos leitura, nossos resultados serão mais restritos ou mais amplos, menos ou mais acolhedores; e a depender do que consideramos que seja um texto literário, nosso olhar mirará ou deixará escapar isto ou aquilo, implicando aí obras, autores, editores, etc.

Neste trabalho, opto por mobilizar ideias amplas do que sejam leitura e literatura, incluindo o oral, o virtual, o novo, o ainda não legitimado ou o legitimado por grupos não hegemônicos ou até mesmo contra-hegemônicos, mas que são tratados pelos/as leitores/as como leitura literária. $\mathrm{E}$ faço isso porque o espaço quase indiscernível das redes sociais da internet recebe e arquiva muitas coisas, muito diversas, embora também ali vá se conformando um sistema que inclui e exclui, valoriza e desvaloriza, dá visibilidade e invisibiliza, legitima e deslegitima, age e reage. Onde está a literatura nas redes? Quais literaturas circulam nas redes?

Nas redes, na conformação que conhecemos, a literatura circula na forma de textos verbais (poemas, contos, romances), publicados em muitos formatos (PDF, livros digitais com extensões diversas), mas também como vídeos (book trailers, gravações caseiras de leituras, filmes profissionais no YouTube, clipes etc.), mas não se trata apenas desse tipo de diferença. As literaturas circulam trazendo autores canônicos ou em vias de serem canonizados, além dos que se consideram periféricos, marginalizados, incômodos, em contato direto uns com os outros, oferecendo ao leitor possibilidades de leitura incontáveis. E não apenas as literaturas, propriamente, ocupam esse espaço digital, mas as conversações sobre elas (e talvez principalmente), na forma de comentários, resenhas (em vídeo ou áudio também), debates, configurando um universo em várias camadas ou órbitas de produtores, críticos e leitores, inclusive em contato efetivo, terminando por friccionarem-se ou não. 
As literaturas das redes, em suas camadas, chegam a quem? Isso é democrático? Ou apenas aparentemente? Sob vários aspectos, as redes são espaços para ao menos três ações nomeadas pelo evento que nos convoca a refletir sobre isto, na forma de verbos: criar, existir e resistir. E esses três verbos nos guiarão pelos casos ou exemplos que passaremos a expor e comentar, sob um viés de gênero (SAPIRO, 2016), sim, uma vez que a literatura feita por mulheres, assim como a crítica e a edição por elas, tem sido preterida em nossa história editorial, no Brasil e no mundo.

\section{Quatro casos criativos e resistentes}

Os casos que mencionarei aqui trazem, em menor ou maior proporção, aspectos da criação, da existência e da resistência nas redes, e todos em estreita relação com a literatura e uma perspectiva de gênero muito oportuna e necessária. Nenhum deles é, ainda, um espaço exclusivo para a produção de textos, mas em todos há um aspecto de criatividade identificável, tanto em suas iniciativas quanto na forma como passam a existir, por meio de sites, contas em plataformas colaborativas ou outras.

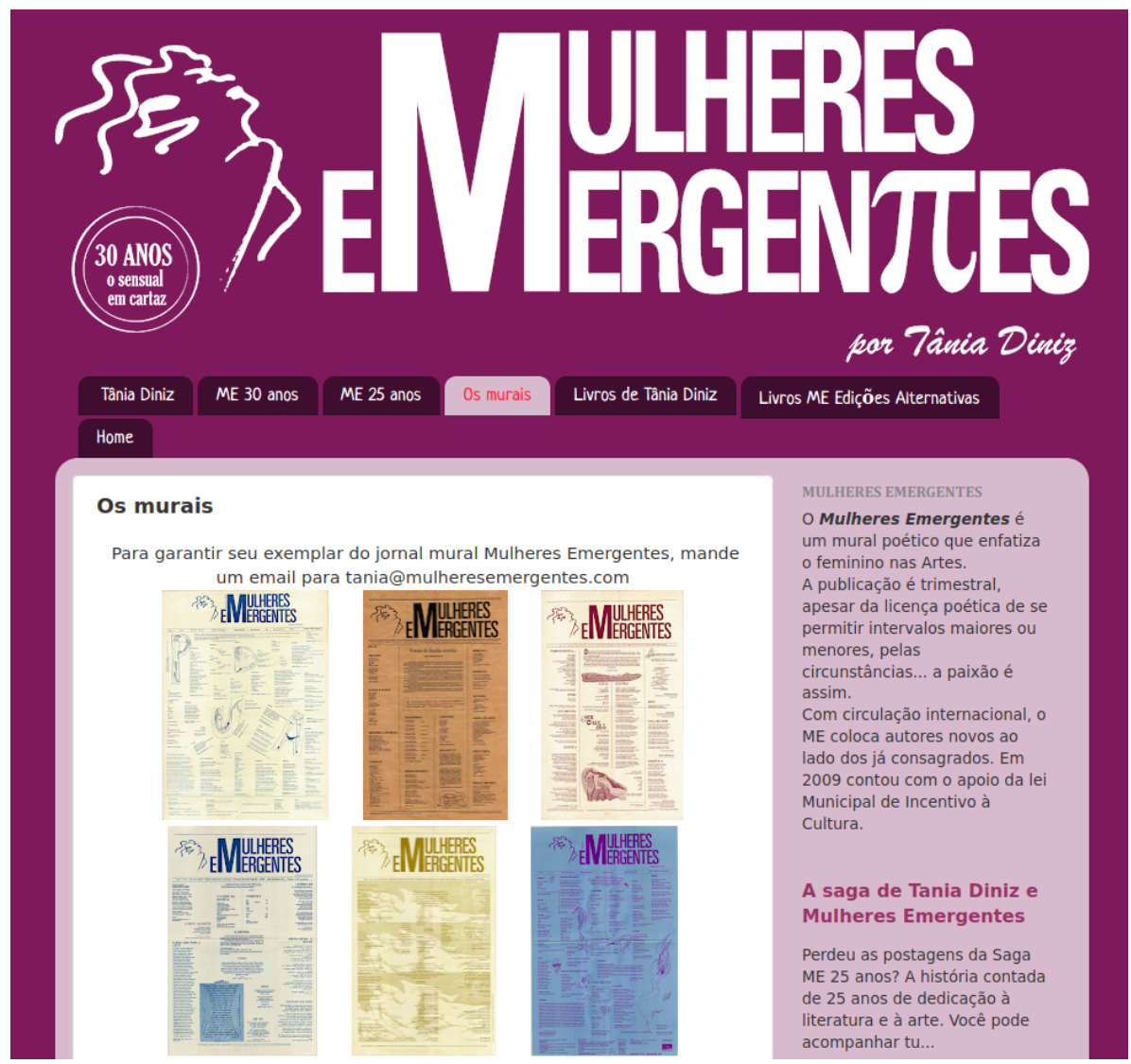

FigurA 1 - Página de download dos murais do site do projeto "Mulheres Emergentes"

(DinIZ, 2007, s.p.). 
Nesse sentido, o site "Mulheres Emergentes" é a iniciativa mais antiga aqui e merece destaque por muitas razões. "Mulheres Emergentes" é o nome de um projeto editorial da escritora e editora mineira Tânia Diniz, ${ }^{1}$ responsável, inicialmente, pela publicação de um mural impresso, de periodicidade trimestral, que reúne a poesia de mulheres há 30 anos. Bem posterior ao mural, obviamente, o site " $\mathrm{Mu}$ lheres Emergentes" funciona como espaço de comunicação com leitoras e leitores, em especial pela aba "Home", em que aparecem postagens da editora, à maneira de um blog. Quase como um diário, Tânia Diniz dá notícias, fala de literatura e posta fotografias, em tom informal. As demais abas, além de explicarem o projeto, funcionam como arquivo, armazenando o inestimável patrimônio que é ter todos os murais do "Mulheres Emergentes", desde o primeiro número, para download (FigurA 1). O projeto também publica livros de poetas e informações sobre prêmios.

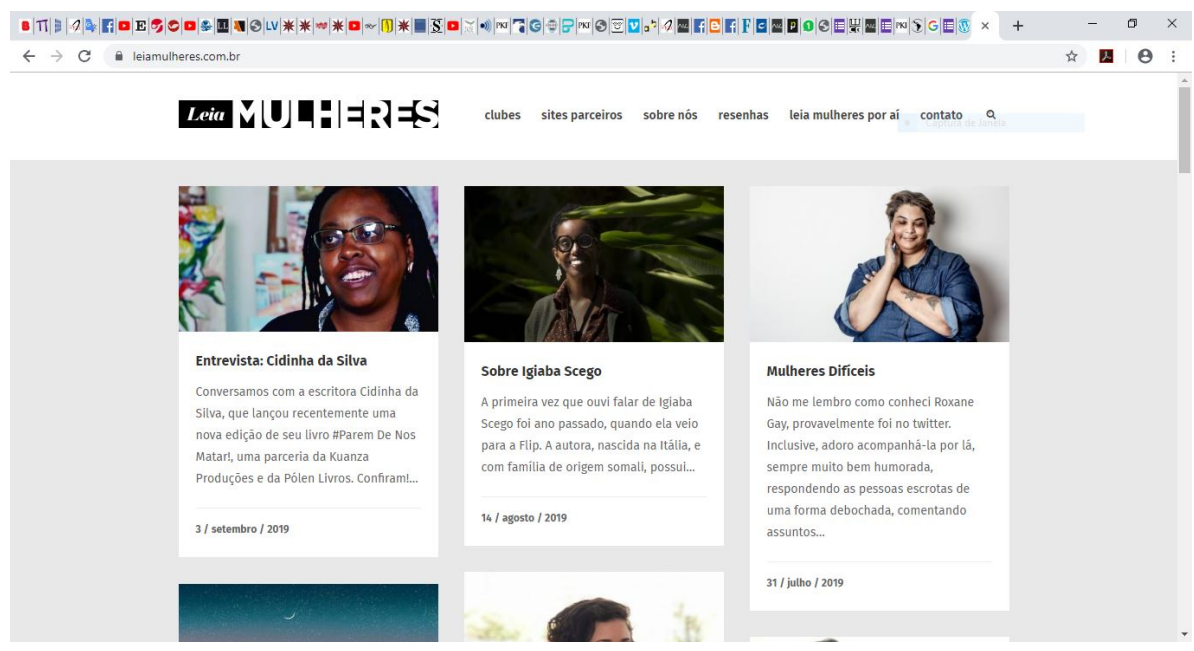

Figura 2 - Página inicial do site do projeto "Leia Mulheres Brasil" (Gomes, LeUenroth e Rodrigues, 2019, s.p.).

O "Mulheres Emergentes" foi, antes de tudo, um mural impresso. Sua criação decorreu do claro projeto político de sua editora: publicar a literatura produzida por mulheres. Para existir e resistir, o "Mulheres Emergentes" encontra na internet um espaço que, funcionando principalmente como arquivo e memória, também permite o acesso de leitores e leitoras de qualquer parte ao material publicado, além de favorecer o contato com a própria Tânia Diniz. O site estabelece uma conexão com interessadas/os, participando de uma rede de produção editorial e literária e lutando contra o apagamento ou o silenciamento dessas autoras. Tratase de um site herdeiro e em integração com a existência do mural impresso (uma espécie de grande cartaz), cuja função é arquivar, visibilizar e promover acesso às/aos leitoras/es, para além da potência do "Mulheres Emergentes" original.

1 Tânia Diniz faleceu precocemente em abril de 2020, vítima de um câncer contra o qual lutou por muitos anos. Ver, sobre sua atuação, Ribeiro (2020). 
Empregando também a força potencializadora das redes digitais, o "\#leiamulheres" é um movimento iniciado em 2014, pela escritora britânica Joanna Walsh. O objetivo era ler mais escritoras, uma vez que o mercado editorial ainda é um espaço de hegemonia masculina. A ideia principal do \#readwomenzo14 é favorecer a visibilidade das autoras e de seus livros. Note-se que o nome do projeto é uma hashtag, elemento típico da comunicação em rede (no Twitter, especialmente).

O \#leiamulheres logo se espalhou pelo mundo e chegou ao Brasil (FigurA 2) pelas mãos das amigas Juliana Gomes, Juliana Leuenroth e Michelle Rodrigues, em 2015, que passaram a promover a leitura de livros escritos por mulheres em encontros presenciais em espaços como livrarias. O movimento, atualmente, conta com mediadoras por todo o Brasil, nas capitais e em cidades do interior. Os elementos de existência e resistência são pilares desse movimento, que se vale de sua origem na linguagem das redes sociais digitais.

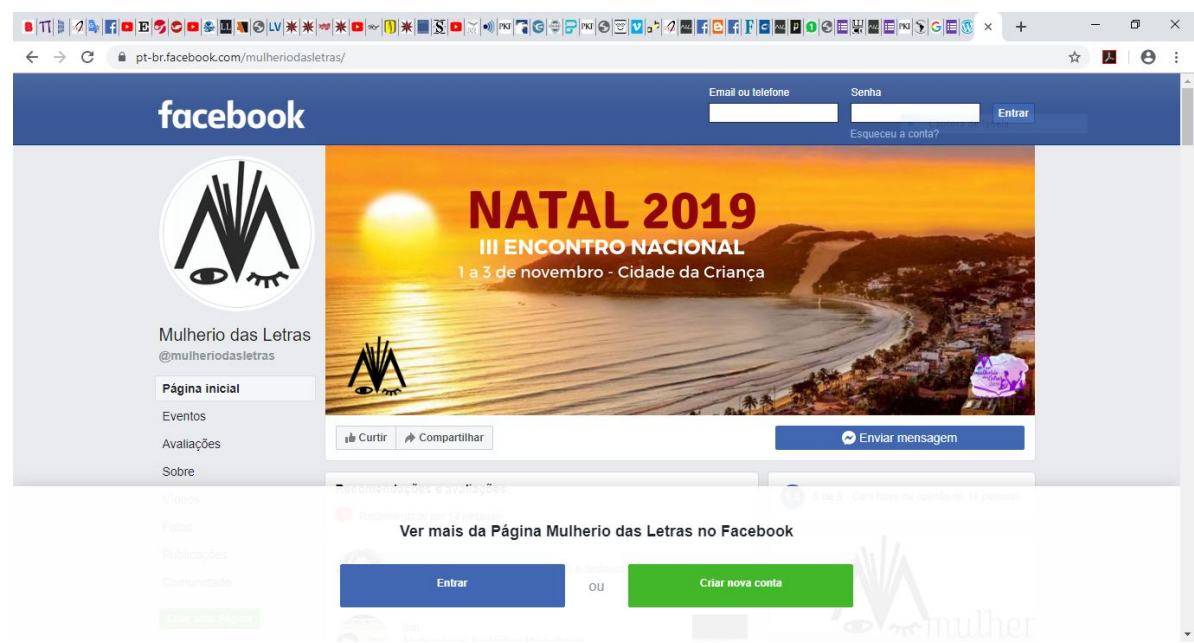

Figura 3 - Página inicial do grupo "Mulherio das Letras" no Facebook (Mulherio das letras, 2017, s.p.).

Também dentro de uma intenção política, com evidente e declarada perspectiva de gênero, o "Mulherio das Letras" é uma iniciativa que tem origem, existência e resistência no Facebook (FIGURA 3), uma rede social de grande força na internet, ao menos desde o início da segunda década do século XXI.

Atendendo ao chamado da escritora Maria Valéria Rezende e outras, o "Mulherio das Letras" foi criado em 2017, sob os seguintes preceitos:

O Mulherio das Letras, criado em 2017, é um coletivo feminista literário, diretamente interessado na expressão pela palavra escrita e oral, com adesão de mais de seis mil mulheres brasileiras residentes no Brasil e no exterior, que se propõe a discutir as questões da mulher nas áreas da arte e da cultura. 
As mulheres reunidas neste encontro, diante da atual e grave conjuntura do Brasil, se comprometem a defender as seguintes pautas:

1. O exercício pleno e irrestrito da democracia;

2. A liberdade de expressão;

3. A garantia e ampliação das políticas públicas para o livro, a leitura, a literatura e as bibliotecas;

4. Salvaguardar os direitos das mulheres, bem como fortalecer e dar visibilidade à literatura produzida por elas;

5. Comprometimento com a defesa da diversidade étnica, de gênero, de classe, de orientação sexual, bem como com a inclusão das mulheres com deficiência;

6. A defesa da educação e, especialmente, da universidade pública, gratuita, laica, de qualidade, inclusiva e aberta à comunidade;

7. A resistência ao sucateamento e desmantelamento dos equipamentos culturais e instituições públicas.

Paralelamente, o Mulherio das Letras realizará ações efetivas nos níveis regional, nacional e internacional, no sentido de manter permanentemente mobilizado o Movimento.

Comissão de redação: Cátia Moraes, Dalila Teles Veras, Giovana Damaceno, Lindevânia Martins, Patrícia Vasconcelos, Rejane Souza, Rosana Chrispim -Carta aprovada com acréscimos e supressões na leitura pública deste documento no encerramento do Encontro. - Guarujá-SP, 4 de novembro de 2018 (CARBONIERI, 2019, s.p.).

Valendo-se exatamente da dinâmica das redes, o primeiro chamado ao "Mulherio" convidava escritoras a "marcarem" outras escritoras no grupo, ampliando assim o alcance deste evento, que, rapidamente, atingiu milhares de mulheres, no Brasil e no exterior. Da criação desse grupo em diante, subgrupos regionais se formaram e várias ações foram executadas, em especial encontros presenciais e publicação de livros (solo ou antologias). Gerado por um movimento de existência e resistência, o "Mulherio das Letras" se estabelece exatamente nas condições sociotécnicas que permitem e favorecem a criação, a existência e a resistência de uma rede social, em constante conversação, congregando milhares de escritoras, em uma plataforma que, a despeito de ter início na web, existe e resiste também presencialmente, marcando uma relação mista muito interessante entre arranjos sociais virtuais e presenciais.

Outra iniciativa que focaliza a produção feminina na literatura é o canal "Bondelê", no YouTube, criado e mantido por Mariana Diniz Mendes (FIGURA 4). Com ampla experiência no mercado editorial convencional, em uma das maiores editoras do país, após mudanças profissionais, Mariana concebeu o "Bondelê" (brincadeira com a expressão "bom de ler"), um canal "independente", roteirizado e apre- 
sentado por ela, em parceria com a cinegrafista Carolina Freitas da Cunha. A descrição que consta na página do canal é: "Seja bem-vinda(o) ao Bondelê, canal com sugestões de livros e entrevistas inéditas com escritoras brasileiras contemporâneas. Mariana Mendes edita, escreve e lê aos montes" (MendEs, 2017, s.p.). No vídeo inaugural, a apresentadora explica os objetivos do "Bondelê":

tenho o objetivo de sugerir leituras de autoras brasileiras contemporâneas. Mulheres que estão escrevendo hoje e sendo publicadas pelo mercado editorial. Além de sugerir essas leituras, pretendo entrevistar também essas escritoras, fazer não só uma breve resenha, um comentário sobre o livro, mas também conversar com essas escritoras sobre as referências que elas têm, sobre o percurso delas até a publicação desse livro, sobre o processo de criação delas, mais até do que falar do próprio livro. Por que esse filtro, esse foco? Primeiro porque eu também sou mulher; segundo porque eu também quero escrever um bom romance, literário, sobretudo; e principalmente porque eu acho legal ter um espaço focado para essa produção (MENDEs, 2017, s.p.).

A intenção política de Mariana Mendes pode ser flagrada em sua vontade de atuar não apenas como escritora, mas principalmente na fundação de um espaço para o comentário, eventualmente a crítica, a circulação da palavra sobre outras escritoras, isto é, auxiliando na existência e na resistência de um discurso sobre livros e autoras, universo no qual ela se inclui, primeiro como comentadora (lugar também raro ou não hegemônico no universo da literatura canônica), depois como escritora, dando voz a outras mulheres, suas contemporâneas.

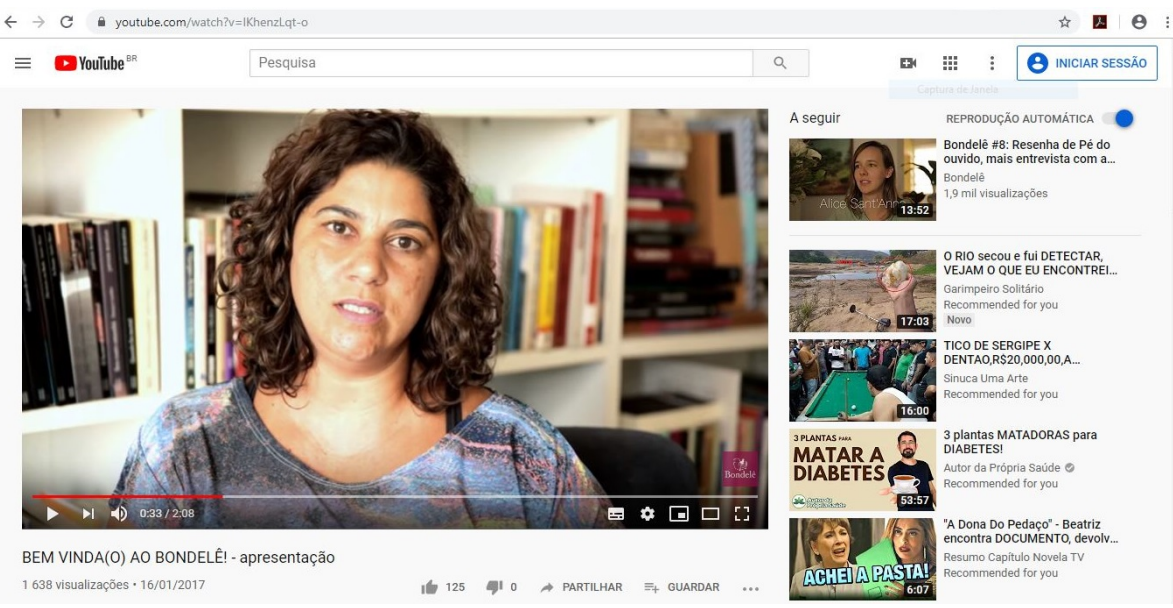

Figura 4 - Página inicial do canal "Bondelê", no YouTube (Mendes, 2017, s.p.).

\section{Ação \& reação}

As quatro iniciativas elencadas e brevemente comentadas na seção anterior se conectam aos fatos que comentarei agora, num contexto em que ser escritora tem 
sido cada vez mais assumido, mais político e, para ficar no espírito do tema maior com que fui provocada nesta oportunidade, num contexto em que a consciência de gênero, entre outras, como a de cor (chamemos assim), enfim se evidencia. Nas redes, a reação a certas ações explode, assume uma velocidade e um alcance que dificilmente alcançaria em outros meios, tornando o debate mais direto, mais acirrado, muitas vezes menos polido do que se ocorresse em outros âmbitos, mas também talvez mais eficaz.

Em tempos de existência explícita e resistência de projetos que buscam manter um discurso sobre as mulheres e suas criações sempre ativo e combativo, é muito difícil que peças ou iniciativas como as que seguem passem despercebidas. O primeiro exemplo é o da peça de divulgação do Prêmio Governo Minas Gerais de Literatura (FIGURA 5), no ano de 2017, um dos mais tradicionais do país e de alto valor financeiro para os vencedores. Supondo que passasse despercebido o texto - o convite à participação - no masculino, em razão de certa suposta universalidade linguística, a imagem não pôde ser ignorada. Embora várias mulheres já tenham sido vencedoras deste prêmio, em distintas categorias (poesia, romance, etc.), a imagem mostra apenas vencedores, homens, brancos e, majoritariamente, maduros. A peça gerou polêmica, mas a reação, embora existente, não teve força para alcançar um efeito prático, como a refacção da campanha ou algo assim.

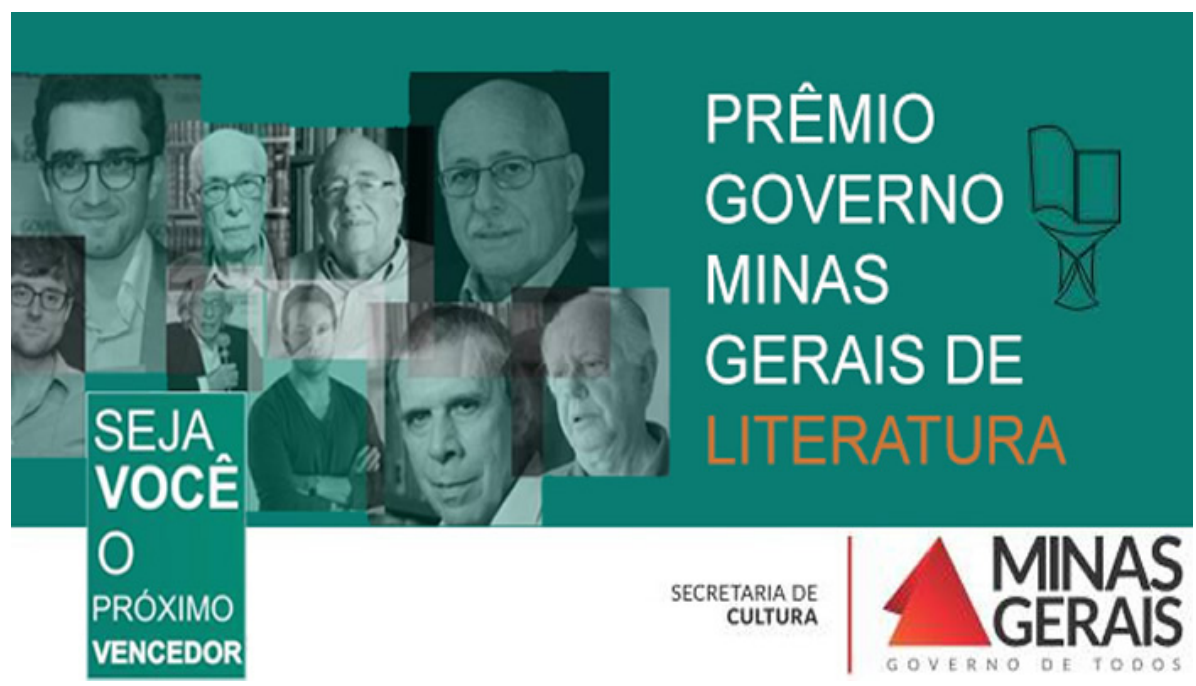

Figura 5 - Peça de divulgação do Prêmio Governo Minas Gerais de Literatura (2017).

Em abril/maio de 2019, nova situação relacionada a eventos literários e imagens volta a acontecer, desta vez em razão do anúncio de um evento do Instituto Moreira Salles, no Rio de Janeiro, que congregaria, segundo a proposta divulgada, um grupo de dezoito poetas, entre homens e mulheres, que representariam a poesia brasileira atual. Uma imagem da "Oficina irritada, poetas falam" com os rostos dos dezoito convidados, sendo onze homens e sete mulheres, passou então a circular nas redes, obtendo reação imediata, em especial de escritores e escritoras negros 
(FIGURA 6). O debate foi acalorado e as explicações de um dos curadores, o poeta Eucanaã Ferraz, na imprensa, pouco ajudaram numa eventual justificativa, se houvesse. Foram convocados a se posicionar os/as poetas, que reagiram à explicação anunciando que deixariam de participar do evento ou publicando uma carta coletiva polida e pouco enfática sobre o caso.

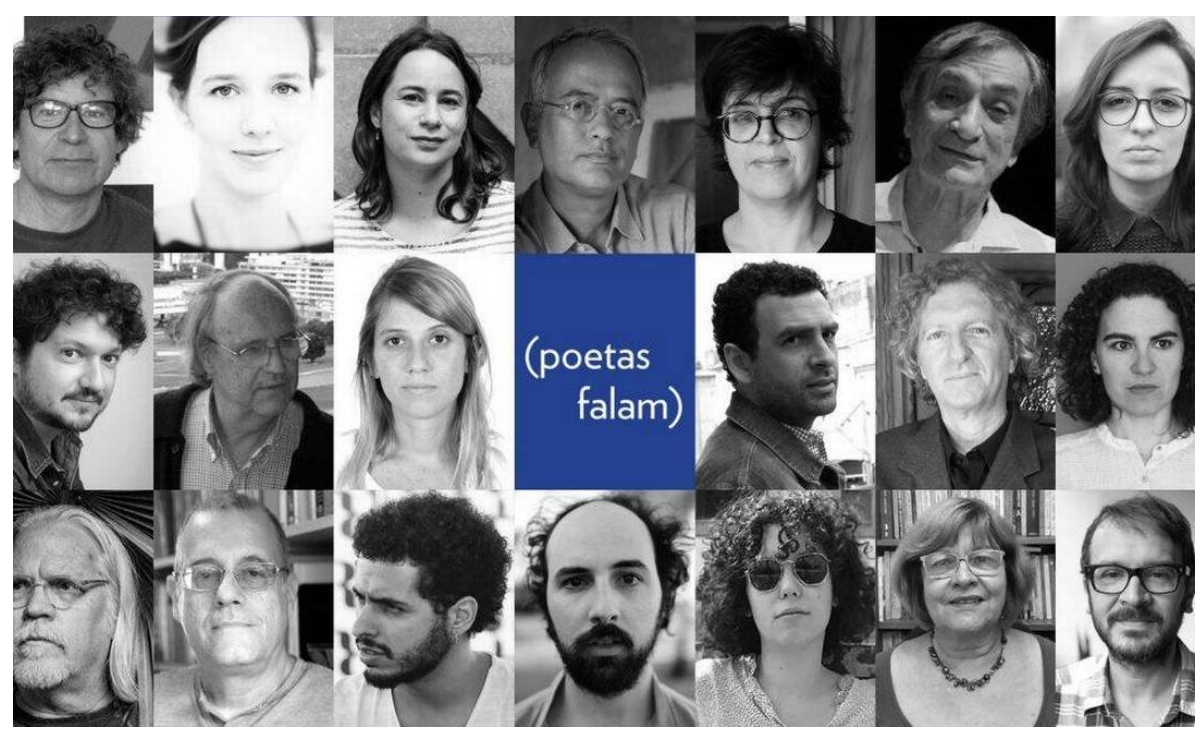

Figura 6 - Peça de divulgação do evento do Instituto Moreira Salles no Rio de Janeiro (2019).

Ao menos dois elementos impressionam nesse tipo de ocorrência, que envolve as redes sociais digitais: a proporção que eles tomam, atingindo as mídias convencionais e de massa; e a velocidade com que o debate acontece e se viraliza. Ao cabo de uma discussão pouco gentil entre uns e outros, o Instituto Moreira Salles - RJ cancelou a "Oficina irritada", nome que, agora, soa premonitório e oportuno. Uma das mais interessantes e inteligentes reações ao evento - e não apenas à peça de divulgação - do Instituto Moreira Salles - RJ está no blog "Impressões de Maria”, criado e conduzido pela estudante de Letras da Universidade Federal de São Paulo, Maria Ferreira, negra de origem baiana.

Maria Ferreira, junto com um texto enfático, informado e direto, citando nomes e tecendo críticas duras ao Instituto Moreira Salles - RJ, ao evento, aos curadores etc., publicou em seu blog uma peça muito semelhante à do evento oficial, empregando mesmas cores e diagramação, mas substituindo os dezoito poetas brancos por dezoito outros, só que negros, com flagrante maior proporção de mulheres, numa espécie de paródia sarcástica ao "Oficina irritada" (FIGURA 7). Mais do que isso, Maria subtitula sua página assim: " 18 poetas brasileiros que a curadoria de literatura do Instituto Moreira Salles deveria conhecer", numa convocação direta ao universo mais total, mais inclusivo e mais atento das literaturas que as gentes do Brasil inteiro hoje produzem (FerReira, 2019, s.p.). A fim de se resguardar e explicar, Maria Ferreira explicita os critérios para sua curadoria da lista e dos po- 
etas da imagem que reage à peça do Instituto Moreira Salles - RJ, até excluindo o único poeta negro que o Instituto teria convidado para o evento.

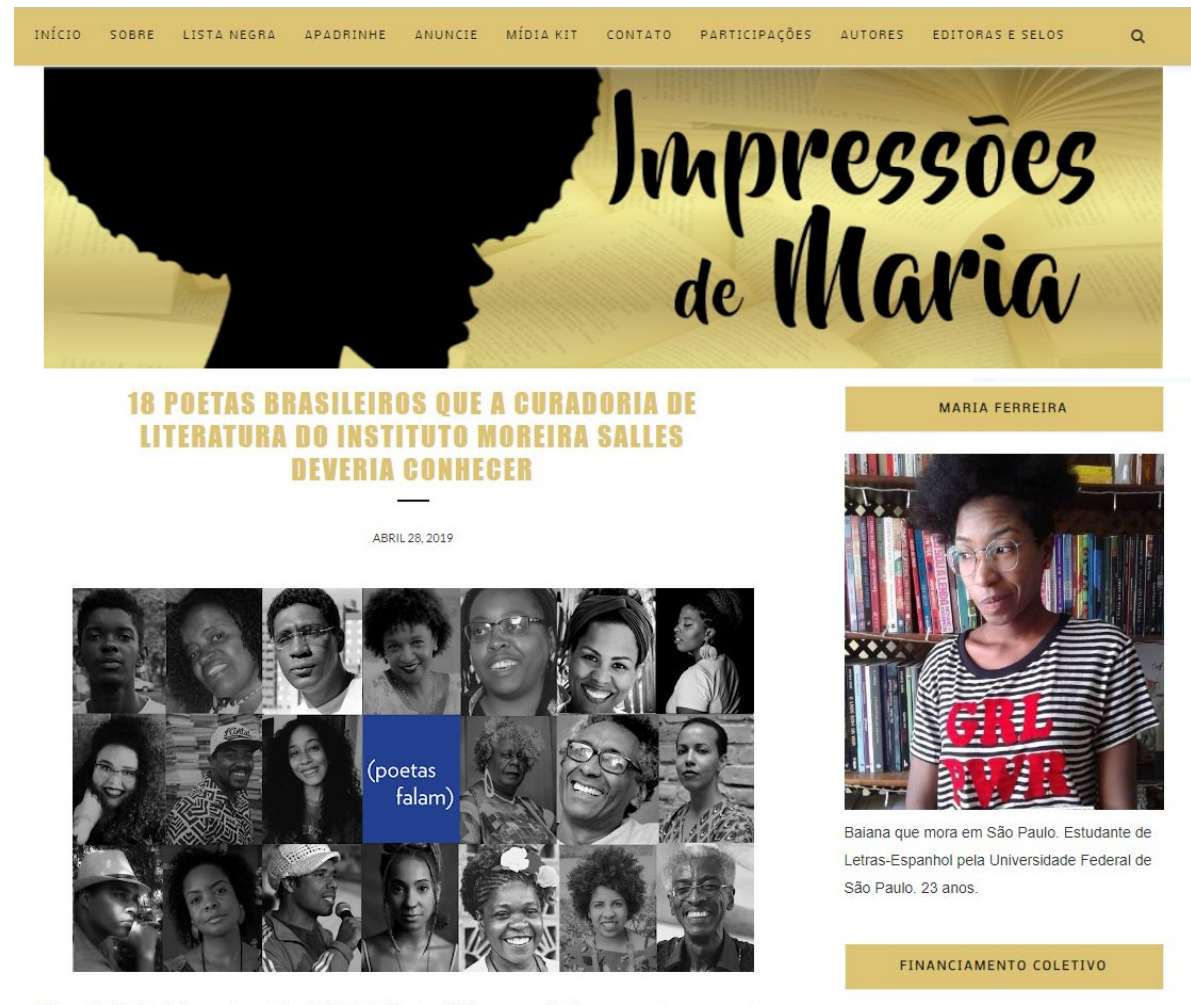

Figura 7 - Página do blog "Impressões de Maria" em resposta ao evento do Instituto Moreira Salles - RJ (FErReIrA, 2019, s.p.).

De fato, a efetiva circulação, a sério, de peças como a do evento do Instituto Moreira Salles - RJ, provoca hoje uma reação imediata, que não tarda a se transformar em um tormento para os envolvidos; de outro lado, é positivamente impressionante que uma reação quase toda sustentada por discursos e debates seja capaz de fazer recuar instituições consolidadas e importantes como o Instituto Moreira Salles - RJ ou qualquer outra. O efeito explosivo alcançado nas redes sociais digitais potencia o que, antes, poderia ficar apenas em um debate a portas fechadas. O que se coloca, no entanto, é quanto esse tipo de tensionamento, envolvendo tantas pessoas e questões (como as de gênero e etnia), influirá numa efetiva reeducação (ou educação mesmo) de nossas percepções como cidadãs e cidadãos.

\section{Algumas coisas que ficam}

Neste texto, as redes de conversações (REcuero, 2009; 2012) na internet favorecem a existência e, em especial, a resistência de projetos que, em sua origem, já buscam a visibilização ou o debate sobre o apagamento das mulheres como escritoras ou, no último caso, das pessoas negras como escritoras. Resistir é oferecer 
dificuldade a que algo ocorra. No entanto, em sendo as questões femininas e negras estruturais, em nosso país (e em vários outros), as iniciativas aqui elencadas são alguns exemplares de uma resistência que talvez tenha se tornado mais organizada e mesmo mais constante depois da existência das redes digitais.

Podemos pensar em resistência como uma força contrária a uma outra, geralmente maior e anterior; e podemos pensar em resistência como o esforço de se manter. São semelhantes, afinal, mas alguns dos casos aqui brevemente mostrados têm mais jeito de uma força contrária à hegemonia de outra força (o patriarcalismo, o machismo, o racismo etc.), enquanto outros desses casos lutam para ficar de pé, há tempos. E, atualmente, usam a internet para existir e resistir, além de criar. E assim seguem, empregando o que surgir de tecnologias ou de plataformas possíveis para enfrentar velhos problemas. Estarão sendo suas vozes ampliadas? Às vezes, parece que sim.

\section{Referências}

Carbonieri, Divanize. Carta aberta do II encontro do Mulherio das Letras 2018. In: Carbonieri et al. Ruído manifesto. Página inicial. 8 mar. 2019. Disponível em: http://ruidomanifesto.org/carta-aberta-do-ii-encontro-nacional-do-mulheriodas-letras-2018/. Acesso em: 2 set. 2019.

CAstells, Manuel. A sociedade em rede. Tradução de Roneide Venancio Majer e Klauss Brandini Gerhardt. São Paulo: Paz e Terra, 1999.

Cosson, Rildo. Letramento literário: teoria e prática. São Paulo: Contexto, 2009.

Dinız. Tânia. Mulheres Emergentes: os murais. 2007. Disponível em: http://www. mulheresemergentes.com/p/murais-me.html. Acesso em: 29 nov. 2019.

EnCONTRo de poetas, sem negros convidados, é cancelado após revolta nas redes sociais. $O$ Globo. Rio de Janeiro, 23 abr. 2019. Disponível em: https: //oglobo.globo.com/cultura/livros/encontro-de-poetas-sem-negros-convidadoscancelado-apos-revolta-nas-redes-sociais-23616913. Acesso em: 2 set. 2019.

Ferreira, Maria. 18 poetas brasileiros que a curadoria de literatura do Instituto Moreira Salles deveria conhecer. In: Impressões de Maria. [blog]. 28 abr. 2019. Disponível em: https://www.impressoesdemaria.com.br/2019/o4/18-poetasbrasileiros-que-curadoria-de.html. Acesso em: 2 set. 2019.

Freire, Paulo. A importância do ato de ler. São Paulo: Cortez, 1982.

Freire, Paulo; MAcedo, Donaldo. Alfabetização: leitura do mundo, leitura da palavra. Rio de Janeiro: Paz e Terra, 1994.

Gomes, Juliana; Leuenroth, Juliana; Rodrigues, Michelle. Leia Mulheres Brasil. Página inicial. c2019. Disponível em: https://leiamulheres.com.br/. Acesso em: 2 set. 2019 . 
Lajolo, Marisa. Do mundo da leitura para a leitura do mundo. São Paulo: Ática, 1993.

Mendes, Mariana Diniz. Bem vinda (o) ao Bondelê! - apresentação. Bondelê. YouTube. 16 jan. 2017. (2min.). Disponível em: https://www.youtube.com/watch?v= IKhenzLqt-o. Acesso em: 2 set. 2019.

Mulherio Das Letras, 2017. Página inicial. Facebook. Disponível em: https:// www.facebook.com/mulheriodasletras/. Acesso em: 2 set. 2019.

Musso, Pierre. A filosofia da rede. In: Parente, André (org.). Tramas da rede: novas dimensões filosóficas, estéticas e políticas da comunicação. Porto Alegre: Sulina, 2010.

Prefeitura Municipal Borda da Mata. Secretaria de Cultura abre inscrições para o Prêmio Governo de Minas Gerais de Literatura 2017. 6 set. 2017. Disponível em: http://www.bordadamata.mg.gov.br/index.php/noticia/item/757-premiogovernodeminas-2017. Acesso em: 2 set. 2019.

Recuero, Raquel. Redes sociais na internet. Porto Alegre: Sulina, 2009.

Recuero, Raquel. A conversação em rede: comunicação mediada pelo computador e redes sociais na internet. Porto Alegre: Sulina, 2012.

Ribeiro, Ana Elisa. Mulheres na edição: o caso de Tânia Diniz e o mural Mulheres Emergentes. Cuadernos del Centro de Estudios de Diseño y Comunicación, 107, 2020. Disponível em: https://pub.palermo.edu/ojs/index.php/cdc/article/view/4203. Acesso em: 15 dez. 2020 .

SAPIRo, Gisèle. La sociología de la literatura. Buenos Aires: Fondo de Cultura Económica, 2016.

Recebido em 29 de janeiro de 2020.

Aprovado em 2 de março de 2020.

\section{Resumo/Abstract/Resumen}

\section{Leitura e literatura nas redes: seis casos sobre criar, existir e resistir}

\section{Ana Elisa Ribeiro}

Neste trabalho, partimos das noções de redes sociais e de conversações em rede, com Manuel Castells e Raquel Recuero, para mostrar seis casos de projetos ou de ocorrências relacionadas à potência das conversações na web, em especial no campo da literatura contemporânea. Quatro desses casos relacionam-se a escritoras que se apropriam dos meios digitais para criar, existir e resistir, alcançando relativo sucesso em seus objetivos de combater a invisibilização e o apagamento de 
vozes e autorias femininas. As três categorias (criar, existir e resistir) são aqui empregadas como pilares da leitura sobre as ações desses seis casos recentes, quais sejam: "Mulheres Emergentes", site da escritora e editora mineira Tânia Diniz; "Mulherio das Letras", coletivo de escritoras de todo o país pelo Facebook; "Leia Mulheres", ação multinacional voltada à leitura de livros escritos por mulheres; "Bondelê", canal da escritora e editora Mariana Mendes no YouTube, cujo objetivo é resenhar e entrevistar escritoras contemporâneas; além dos eventos reativos ocorridos em relação às peças de divulgação de um prêmio literário mineiro e de um evento literário do Instituto Moreira Salles (RJ). Em todos os casos, é possível observar como as conversações potenciadas pelas redes digitais são capazes de desarticular ou, no mínimo, incomodar o que esteve posto, dentro e fora do computador.

Palavras-chave: literatura, gênero, redes sociais, escritoras.

\section{Reading and literature online: six cases of creating, existing and resisting}

\section{Ana Elisa Ribeiro}

In this work we start from the concepts of social networks and online conversations, with the authors Manuel Castells and Raquel Recuero, to analyse six cases related to the power of online conversations, especially in the field of Brazilian contemporary literature. Four of these cases relate to women writers who make use of digital media to create, exist and resist, achieving relative success in their goals of fighting the invisibility and erasure of female voices and authorship. The three categories (to create, to exist and to resist) are used here as the pillars of a certain reading about the actions of these six recent cases, namely: Mulheres Emergentes, the website of writer and editor Tânia Diniz; Mulherio das Letras, a Facebook collective of writers from all over the country (Brazil); Leia Mulheres, a multinational initiative aimed at the reading of books written by women; Bondelê, a Youtube channel by writer and editor Mariana Mendes, whose goal is to review and interview contemporary (female) writers; besides these four initiatives, we make some considerations about the reactive events that occurred in relation to the publicity pieces of a Minas Gerais literary prize and a literary event of Instituto Moreira Salles (RJ). In all of these cases, it is possible to observe how conversations enhanced by digital networks are capable of disarticulating or, at the very least, disturbing what has been established, on and off the computer.

Keywords: literature, gender, social networks, writers.

\section{Lectura y literatura en las redes: seis casos sobre creación, existencia y resistencia}

\section{Ana Elisa Ribeiro}

En este artículo, a partir de las nociones de redes sociales y de conversaciones en red, con los autores Manuel Castells y Raquel Recuero, comentamos seis casos de 
proyectos relacionados con la potencia de las conversaciones en Internet, especialmente en el campo de la literatura contemporánea brasileña, y de escritoras que se apropian de los medios digitales con la finalidad de crear, existir y resistir. A través de ellos, estas mujeres alcanzan un éxito relativo en su objetivo de pelear contra la invisibilización y el silenciamento de sus voces. Las tres categorías propuestas: crear, existir y resistir; son aplicadas aquí como ejes de la lectura de seis casos recientes: Mulheres Emergentes, sitio web de la escritora y editora brasileña Tânia Diniz; Mulherio das Letras, un colectivo de escritoras en Facebook; Leia Mulheres, una iniciativa multinacional para el incentivo de la lectura de libros escritos por mujeres; Bondelê, el canal en YouTube de la escritora y editora Mariana Mendes, cuyo objetivo es el de comentar y entrevistar escritoras contemporáneas; además de los eventos de reacción a las piezas promocionales de un premio literario en el estado de Minas Gerais y de un evento literario del Instituto Moreira Salles (Rio de Janeiro). En todos estes casos es posible observar como las conversaciones potenciadas por las redes digitales pueden desequilibrar o, al menos, interferir sobre lo establecido, dentro y fuera de los ordenadores.

Palabras clave: literatura, género, redes sociales, escritoras. 